\title{
Crystallization kinetics of sea-salt aerosols studied by high-speed photography
}

\author{
QIAN ZhengGang, WANG Feng, ZHENG YuXia, YU JunYing \& ZHANG YunHong* \\ Institute of Chemical Physics, Beijing Institute of Technology, Beijing 100081, China
}

Received May 9, 2011; accepted September 14, 2011; published online January 3, 2012

\begin{abstract}
Morphological changes with decreasing relative humidity $(\mathrm{RH})$ of supersaturated sea-salt aerosol droplets on a quartz substrate were observed using a high-speed video-camera. Stable gypsum $\left(\mathrm{CaSO}_{4} \cdot 2 \mathrm{H}_{2} \mathrm{O}\right)$ or the metastable hemihydrate $\left(\mathrm{CaSO}_{4} \cdot 0.5 \mathrm{H}_{2} \mathrm{O}\right)$ were precipitated as the RH decreased. The dynamic process of crystal growth under steady-state humidity was studied by controlling the RH; the metastable hemihydrate was precipitated at $70.5 \%-77.1 \% \mathrm{RH}$, and the apparent crystal growth rate was between 1.42 and $2.33 \mu \mathrm{m}^{3} / \mathrm{s}$. Stable gypsum was formed at $80.7 \%-82.2 \% \mathrm{RH}$, and the apparent crystal growth rate was between 0.70 and $0.81 \mu \mathrm{m}^{3} / \mathrm{s}$.
\end{abstract}

high-speed photography, sea-salt aerosols, crystallization dynamics

Citation: Qian Z G, Wang F, Zheng Y X, et al. Crystallization kinetics of sea-salt aerosols studied by high-speed photography. Chin Sci Bull, 2012, 57: 591-594, doi: $10.1007 / \mathrm{s} 11434-011-4907-\mathrm{Z}$

Supersaturated aerosols are common in nature. The achievement of a supersaturated state is considered to be the result of the suppression of both homogeneous and heterogeneous nucleations in aerosols with tiny volumes [1]. The crystallization dynamics of supersaturated aerosols and the formation of a metastable solid-phase are basic problems in crystal growth and atmospheric science. In the supersaturated state, the crystallization of aerosol droplets is mainly affected by kinetic factors, resulting in metastable solids instead of thermodynamically stable ones [2-4]. There have been few experimental investigations of the nucleation mechanisms of supersaturated aerosols and the kinetics of crystal growth because of a lack of effective methods. Recently, Ciobanu et al. [5] analyzed the distribution of the initial growth sites of ammonium sulfate crystals using a high-speed video-camera and found that the vicinity of the liquid/vapor interface, rather than the droplet, is the preferred nucleation site. Hindmarsh et al. [6] observed surface and volume nucleation phenomena in undercooled sucrose solution droplets with a high-speed video-camera and ana-

\footnotetext{
*Corresponding author (email: yhz@bit.edu.cn)
}

lyzed the surface nucleation mechanism.

Sea-salt aerosols (SSAs), which are an important component of marine aerosols, are produced predominantly by bubble bursting and the formation of spume droplets as a result of the action of the wind on the ocean. Although SSAs have been found to precipitate stable gypsum or the metastable hemihydrate in the high-humidity range [7], the formation conditions of $\mathrm{CaSO}_{4} \cdot 0.5 \mathrm{H}_{2} \mathrm{O}$ or $\mathrm{CaSO}_{4} \cdot 2 \mathrm{H}_{2} \mathrm{O}$ crystals are unclear, especially with regard to their growth kinetics; the growth kinetics is important in understanding the phase-separation process as well as the nucleation of $\mathrm{NaCl}$ crystals [8].

High-speed photography is one of the most effective methods for the investigation of instantaneous processes. The combination of a high-speed video-camera and an optical microscope can give a time resolution of $2 \mu$ s and a spatial resolution of $1 \mu \mathrm{m}$ [9]. In this paper, we study the morphological changes with decreasing relative humidity (RH) of supersaturated SSA droplets to investigate the nucleation mechanism and kinetics of crystal growth of SSAs. Dynamic images of calcium sulfate crystallization are captured using a high-speed video-camera so that the crystal growth rate 
can be calculated. Finally, kinetic equations are obtained.

\section{Experimental}

\subsection{SSA droplets preparation}

Sea-water samples were taken from the sea in Qingdao. SSA droplets were injected onto a quartz substrate using a syringe. The quartz substrate was then fixed to the bottom of a chamber, and the chamber was sealed with a thin transparent polyethylene film. The RH in the chamber was adjusted by mixing streams of water-saturated $\mathrm{N}_{2}$ and dry $\mathrm{N}_{2}$ at controlled flow rates. The RH in the chamber was determined using a humidity temperature meter (Centertek Center 310, Taiwan, China) with an accuracy of $\pm 2.5 \%$ in the chamber.

\subsection{High-speed photographic investigations}

Figure 1 shows a schematic diagram of the experimental setup for the high-speed photographic investigations of the crystallization kinetics of supersaturated SSA droplets. A combination of an optical microscope (BMX, Shanghai) and a high-speed CMOS (Complementary Metal-Oxide-Semiconductor) video-camera (MS55K, MegaSpeed Corp., Canada) was used to track the morphological changes of SSA droplets at a given RH. The high-speed CMOS camera was set at 100 frames per second. In the initial step, high RHs $(>90 \%)$ were maintained in the chamber using a stream of water-saturated $\mathrm{N}_{2}$ at a controlled flow rate of $400 \mathrm{~mL} / \mathrm{min}$. After equilibrium was reached, the $\mathrm{RH}$ was decreased in stages by controlling the flow rates of water-saturated $\mathrm{N}_{2}$ and dry $\mathrm{N}_{2}$. As the RH decreased, the morphological changes of the SSA droplets were recorded using the high-speed CMOS camera. The images were used to evaluate the crystal sizes and volume during the dynamic crystal growth process. The measurements were made at ambient temperatures of $22-24^{\circ} \mathrm{C}$.

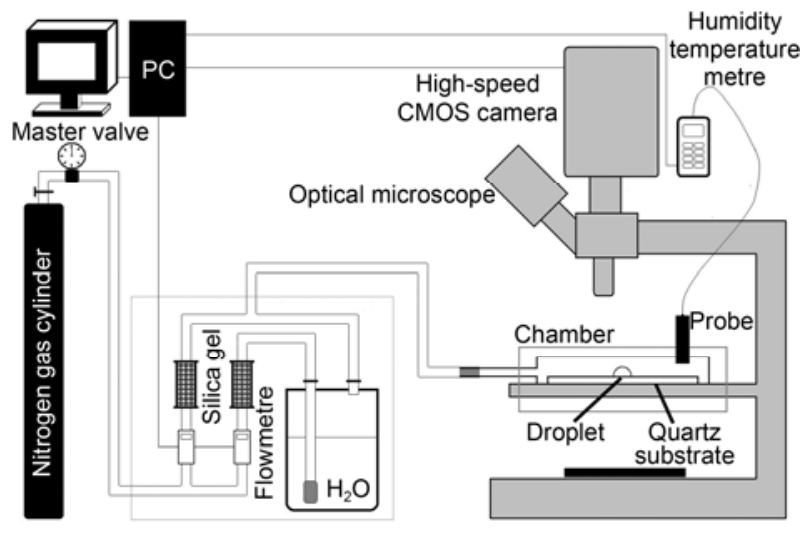

Figure 1 Schematic diagram of the experimental setup for the high-speed photographic investigations of the crystallization dynamics of supersaturated SSA droplets.

\section{Results and discussion}

Previous studies suggested that supersaturated SSAs effloresced to form a metastable hemihydrate or stable gypsum [7]. In the present study, we focused on the morphological changes and kinetic processes of crystal growth. Droplets of diameter of $100-150 \mu \mathrm{m}$ on a quartz substrate were used for high-speed photographic investigations. In the initial stage, with a high RH (>90\%), the droplets were thick and appeared dark. With decreasing RH, the droplets became increasingly bright as the droplets became thinner. At a steady RH in the range $70.5 \%-77.1 \%$, double-spherical crystals were usually observed; confocal Raman spectroscopy showed that these were the hemihydrate. When the RH decreased to $80.7 \%-82.2 \%$, rod-like crystals were precipitated, and confocal Raman spectroscopy showed that these were gypsum. The dynamic crystal growth process was monitored for periods of 15-120 s. The high-speed CMOS camera was set at 100 frames per second for tracking the morphological changes. The dynamic crystal growth process was investigated by analyzing the images; this will be discussed in the following sections.

\subsection{Dynamic images of calcium sulfate crystallization}

The morphological changes with time (0-129 s) of a SSA droplet in the hemihydrate precipitation stage are shown in Figure 2(a). The humidity curve is shown at the top of Figure 2(a). During hemihydrate crystal growth, the RH decreases from $73.6 \%$ to $71.7 \%$. Metastable hemihydrate crystallization appears in the region enclosed in a black box. If the frame before a crystal seed formed is set as the zero moment, the crystal size reached $2 \mu \mathrm{m}$ at $6 \mathrm{~s}$. Double-sphere structures can be recognized; these are twin structures [10]. Initially, the radius of the twin grows rapidly. With increasing time, the rate of increase of the radius gradually decreases. The radius reaches $7 \mu \mathrm{m}$ at $129 \mathrm{~s}$.

The morphological changes with time (0-105 s) of the SSA droplet in the gypsum precipitation stage are shown in Figure 2(b). The humidity curve is shown at the top of Figure 2(b). When the RH decreases to $82.2 \%$, rod-like gypsum is formed in the bottom region of the droplet (marked with a black box). The RH is constant during the period of gypsum growth. The frame before the appearance of the crystal seed is set as the zero moment. The crystal reaches $4 \mu \mathrm{m}$ at $6 \mathrm{~s}$. Initially, the lengths of the rod-like gypsum increase rapidly, but later the lengths of the crystals increase more slowly. The length reaches $17 \mu \mathrm{m}$ at $105 \mathrm{~s}$.

\subsection{Kinetic equations}

Figure 3 shows six sets of experimental data for the crystal volume $(V)$ versus time $(t)$. The crystal volumes were obtained by analyzing the images using the image analysis 

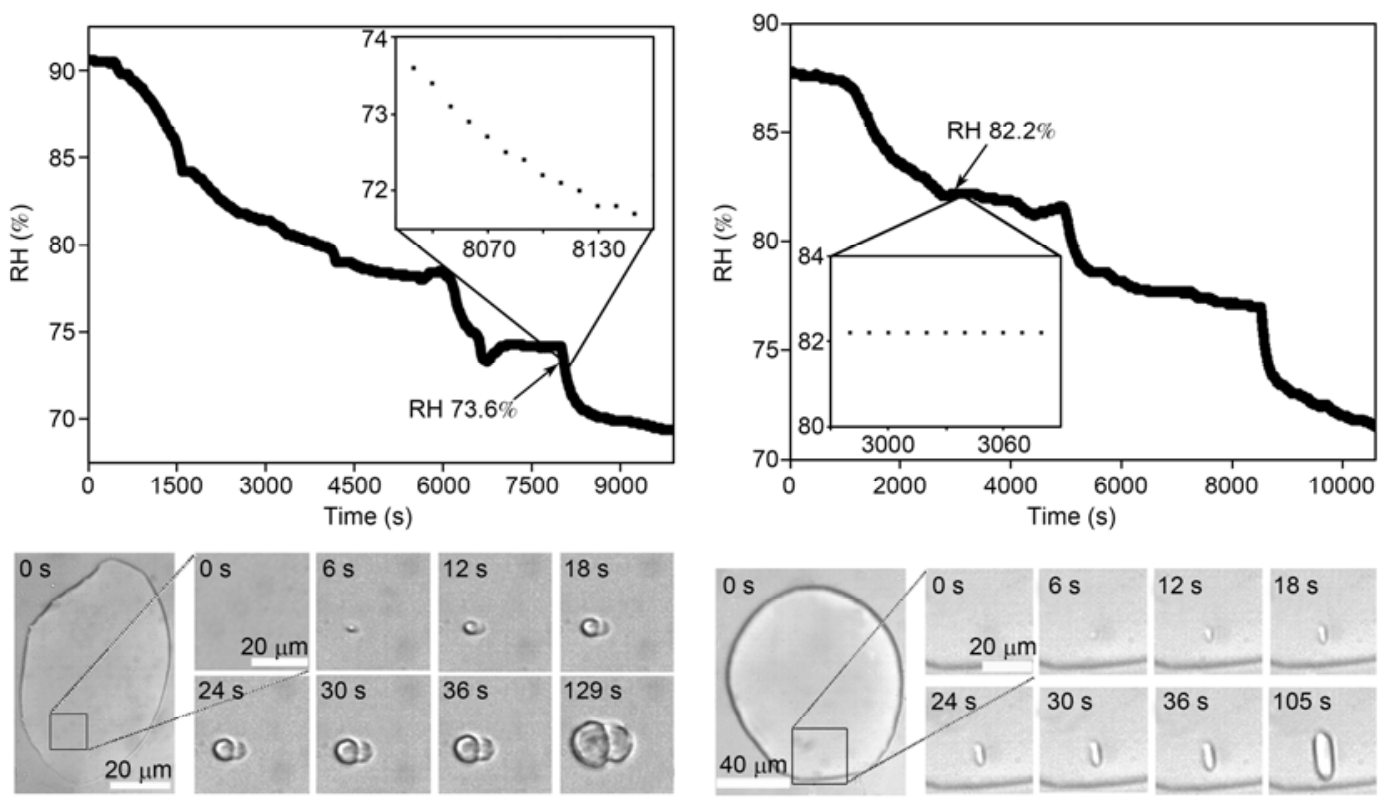

(a)

(b)

Figure 2 Morphological changes with time of SSA droplets in calcium sulfate crystallization. (a) $\mathrm{CaSO}_{4} \cdot 0.5 \mathrm{H}_{2} \mathrm{O}$ was precipitated at $73.6 \% \mathrm{RH}$ and (b) $\mathrm{CaSO}_{4} \cdot 2 \mathrm{H}_{2} \mathrm{O}$ was precipitated at $82.2 \% \mathrm{RH}$.

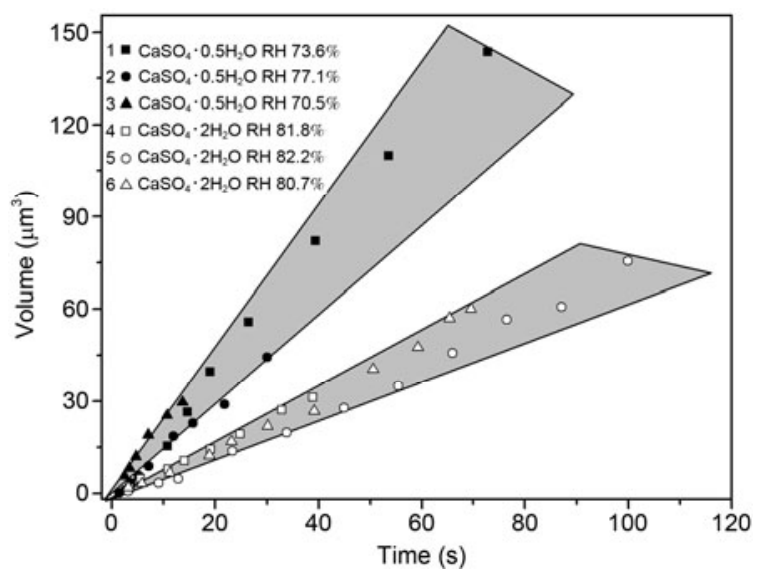

Figure 3 Generation of crystals from SSA droplets at different relative humidities; plots of crystal volumes with time and linear fitting equations (匹: $V=2.01 t, \bullet: V=1.42 t, \boldsymbol{\Delta}: V=2.33 t, \square: V=0.79 t, \circ: V=0.70 t$, and $\Delta$ : $V=0.81 t)$.

software Image $\mathbf{J}$ [5]. The crystal areas can be obtained directly by selecting the image contour with the Image $\mathbf{J}$ software. The crystal heights can be calculated from the brightness contrast [11], also obtained with the Image J software. The crystal volume can be calculated by multiplying the area by the height. Good linear relationships were found between the volume of the crystal and time for the six samples. The linear fitting equations are $V=2.01 t, V=1.42 t$, and $V=2.33 t$ for the $\mathrm{CaSO}_{4} \cdot 0.5 \mathrm{H}_{2} \mathrm{O}$ crystals produced at $73.6 \%, 77.1 \%$, and $70.5 \% \mathrm{RH}$, respectively, and $V=0.79 t$, $V=0.70 t$, and $V=0.81 t$ for the $\mathrm{CaSO}_{4} \cdot 2 \mathrm{H}_{2} \mathrm{O}$ crystals produced at $81.8 \%, 82.2 \%$, and $80.7 \% \mathrm{RH}$, respectively. The volume-time data appear in two separate regions for the hemihydrate and gypsum, as shown by the shaded areas in Figure 3. Within the observation time, the crystal growth rate $(R=\mathrm{d} V / \mathrm{d} t)$ remains constant; the rate law of the crystal growth is $R=k \beta^{n}[12,13]$, where $\beta$ is the growth affinity, $k$ is the growth rate constant, and $n$ is an apparent order constant. For the hemihydrate,

$$
\beta=\ln \frac{\left[\mathrm{Ca}^{2+}\right]\left[\mathrm{SO}_{4}^{2-}\right]\left[\mathrm{H}_{2} \mathrm{O}\right]^{0.5}}{\left[\mathrm{Ca}^{2+}\right]_{\mathrm{eq}}\left[\mathrm{SO}_{4}^{2-}\right]_{\mathrm{eq}}\left[\mathrm{H}_{2} \mathrm{O}\right]_{\mathrm{eq}}^{0.5}}=\ln \frac{\left[\mathrm{Ca}^{2+}\right]\left[\mathrm{SO}_{4}^{2-}\right][\mathrm{RH}]^{0.5}}{K_{\text {sp hem }}} .
$$

For gypsum,

$$
\beta=\ln \frac{\left[\mathrm{Ca}^{2+}\right]\left[\mathrm{SO}_{4}^{2-}\right]\left[\mathrm{H}_{2} \mathrm{O}\right]^{2}}{\left[\mathrm{Ca}^{2+}\right]_{\mathrm{eq}}\left[\mathrm{SO}_{4}^{2-}\right]_{\mathrm{eq}}\left[\mathrm{H}_{2} \mathrm{O}\right]_{\mathrm{eq}}^{2}}=\ln \frac{\left[\mathrm{Ca}^{2+}\right]\left[\mathrm{SO}_{4}^{2-}\right][\mathrm{RH}]^{2}}{K_{\mathrm{sp}, \mathrm{gyp}}},
$$

where $\left[\mathrm{Ca}^{2+}\right],\left[\mathrm{SO}_{4}^{2-}\right]$, and $\left[\mathrm{H}_{2} \mathrm{O}\right]$ are the activities of the corresponding species. The subscript eq refers to equilibrium conditions. $K_{\text {sp,hem }}=10^{-2.22}$ and $K_{\text {sp,gyp }}=10^{-2.85}$ are the solubility products for the hemihydrate and gypsum, respectively, in sea-water at $25^{\circ} \mathrm{C}$ [14]. The apparent order $n$ of gypsum growth in the presence of an electrolyte such as $\mathrm{NaCl}$ is approximately 1.0 and the order of the hemihydrate growth is about 2.0 at high relative supersaturation when $\beta$ is bigger than $1[12,13]$. Table 1 summarizes the initial concentrations of $\mathrm{Ca}^{2+}$ and $\mathrm{SO}_{4}^{2-}$ at the RHs corresponding to hemihydrate or gypsum formation, and the calculated results.

Obviously, the hemihydrate precipitates at a lower RH, with a faster crystal growth rate and a quicker desiccation process, in which the RH decreases by about $2 \%$. However, gypsum can be observed to precipitate at higher RHs, with a 
Table 1 Experimental conditions and results

\begin{tabular}{|c|c|c|c|c|c|c|c|}
\hline Expt. No. & $\mathrm{RH}(\%)$ & Crystals & $\mathrm{Ca}^{2+}(\mathrm{mol} / \mathrm{L})$ & $\mathrm{SO}_{4}^{2-}(\mathrm{mol} / \mathrm{L})$ & $\beta$ & $R\left(\mu \mathrm{m}^{3} / \mathrm{s}\right)$ & $k\left(\mu \mathrm{m}^{3} / \mathrm{s}\right)$ \\
\hline 1 & 73.6 & Hemihydrate & 0.135 & 0.372 & 1.95 & 2.01 & 0.53 \\
\hline 2 & 77.1 & Hemihydrate & 0.119 & 0.330 & 1.74 & 1.42 & 0.47 \\
\hline 3 & 70.5 & Hemihydrate & 0.147 & 0.406 & 2.11 & 2.33 & 0.53 \\
\hline 4 & 81.8 & Gypsum & 0.098 & 0.272 & 2.56 & 0.79 & 0.31 \\
\hline 5 & 82.2 & Gypsum & 0.097 & 0.267 & 2.52 & 0.70 & 0.28 \\
\hline 6 & 80.7 & Gypsum & 0.103 & 0.285 & 2.62 & 0.81 & 0.31 \\
\hline
\end{tabular}

slower crystal growth rate and a slower desiccation process, in which the RH remains constant during the crystallization. It also follows that, for crystals of the same type, the lower the RH at which the crystals precipitate, the faster the crystal growth rate will be. The growth rate constant $k$ of crystals of the same type is almost the same. Both $R$ and $k$ are larger for the hemihydrate than they are for gypsum.

\section{Conclusions}

In this work, SSA droplets on a quartz substrate were observed using a high-speed video-camera to investigate their morphological changes with decreasing $\mathrm{RH}$. A metastable hemihydrate is precipitated at low RHs (70.5\%-77.1\%), with a fast crystal growth rate and a quick desiccation process. However, stable gypsum is precipitated at higher RHs $(80.7 \%-82.2 \%)$, with a slower crystal growth rate and a slower desiccation process. The RH plays an important role in the course of crystallization. A good linear relationship between the crystal volume and time is found. The slope is the crystal growth rate $R$ and the growth rate constant $k$ can be calculated from the formula $R=k \beta^{n}$. Both $R$ and $k$ of the hemihydrate are larger than those of gypsum. It can be concluded that the lower the $\mathrm{RH}$ at which the crystals are precipitated, the faster the crystal growth rate $R$ will be.

This work was supported by the National Natural Science Foundation of China (20933001, 41175119 and 20873006), the National Basic Research Program of China (2009CB220100), and the Trans-Century Training Program Foundation for the Talents.
1 Martin S T. Phase transitions of aqueous atmospheric particles. Chem Rev, 2000, 100: 3403-3453

2 Chan C K, Peng C G. The water cycles of water-soluble organic salts of atmospheric importance. Atmos Environ, 2001, 35: 1183-1192

3 Linke W F. Solubilities, Inorganic and Metal-Organic Compounds. Vol.7. 4th ed. Washington DC: American Chemical Society, 1958

4 Tang I N, Fung K H, Imer D G, et al. Phase transformation and metastability of hygroscopic microparticles. Aerosol Sci Technol, 1995, 23: 443-453

5 Ciobanu V G, Marcolli C, Krieger U, et al. Efflorescence of ammonium sulfate and coated ammonium sulfate particles: Evidence for surface nucleation. J Phys Chem A, 2010, 114: 9486-9495

6 Hindmarsh J P, Russell A B, Chen X D. Observation of the surface and volume nucleation phenomena in undercooled sucrose solution droplets. J Phys Chem C, 2007, 111: 5977-5981

7 Xiao H S, Dong J L, Wang L Y, et al. Spatially resolved Micro-Raman observation on the phase separation of effloresced sea salt droplets. Environ Sci Technol, 2008, 42: 8698-8702

8 Cheng R J, Blanchard D C, Cipriano R J. The formation of hollow sea-salt particles from the evaporation of drops of seawater. Atmos Res, 1988, 22: 15-25

9 Wang F, Zhao L J, Zhang Y H. Crystallization dynamics of supersaturated $\mathrm{NaClO}_{4}$ aerosols studied by high-speed photography. Chin Sci Bull, 2008, 53: 2139-2144

10 Mullin J W. Crystallization. 3rd ed. Oxford: Butterworth-Heinemann, 1993. 23

11 Van Driessche A E S, Garcia-Ruiz J M, Delgado-Lopez J M, et al. In situ observation of step dynamics on gypsum crystals. Cryst Growth Des, 2010, 10: 3909-3916

12 Yang L C, Wu Z B, Guan B H, et al. Growth rate of $\alpha$-calcium sulfate hemihydrate in $\mathrm{K}-\mathrm{Ca}-\mathrm{Mg}-\mathrm{Cl}-\mathrm{H}_{2} \mathrm{O}$ systems at elevated temperature. J Cryst Growth, 2009, 311: 4518-4524

13 Witkamp G J, van der Eerden J P, Van Rosmalen G M. Growth of gypsum 1. Kinetics. J Cryst Growth, 1990, 102: 281-289

14 William L M, Ruth S. Aqueous systems at high temperature. Solubility to $200^{\circ} \mathrm{C}$ of calcium sulfate and its hydrates in sea water and saline water concentrates, and temperature-concentration limits. J Chem Eng Data, 1968, 13: 83-93

Open Access This article is distributed under the terms of the Creative Commons Attribution License which permits any use, distribution, and reproduction in any medium, provided the original author(s) and source are credited. 